\title{
An Overview on Bioreactor Design, Prototyping and Process Control for Reproducible Three-Dimensional Tissue Culture
}

\author{
Ralf Pörtner and Christoph Giese
}

\begin{abstract}
Bioreactor systems play an important role in tissue engineering, as they enable reproducible and controlled changes to be made in specific environmental factors. They can also provide the technical means to perform controlled studies aimed at understanding specific biological, chemical, or physical effects. Furthermore, bioreactors allow for a safe and reproducible production of tissue constructs. For later clinical applications, the bioreactor system should be an advantageous method in terms of low contamination risk, ease of handling, and scalability. With respect to drug screening, the main challenge is the efficient, reproducible handling of a large quantity of tissue constructs in parallel (high-throughput screening). To date, the goals and expectations of bioreactor development have been fulfilled only to some extent, as bioreactor design in tissue engineering is very complex and still at an early stage of development, especially for use in drug screening. In this chapter, important aspects of bioreactor design are summarized, and an overview of existing concepts is provided. An artificial immunosystem will be used as an example to demonstrate how an increased fundamental understanding of biological, biochemical, and engineering aspects can significantly improve the properties of 3D tissue constructs.
\end{abstract}

2.1

Introduction

Tissue engineering, which means the generation of artificial three-dimensional (3D) tissues, is intended as a powerful tool for regenerative medicine and for drug screening [1-5]. The goal of tissue engineering can be defined as the development of cell-based substitutes to restore, maintain, or improve tissue function. These substitutes should have organ-specific properties with respect to biochemical activity, microstructure, mechanical integrity and biostability [2]. Cell-based therapy concepts include: (1) the direct transplantation of isolated cells; (2) the implantation of a bioactive scaffold for the stimulation of cell growth within the original tissue; and (3) the implantation of a 3D biohybrid structure of a scaffold and cultured

\footnotetext{
Drug Testing In Vitro: Breakthroughs and Trends in Cell Culture Technology Edited by Uwe Marx and Volker Sandig

Copyright (C) 2007 WILEY-VCH Verlag GmbH \& Co. KGaA, Weinheim ISBN: 978-3-527-31488-1
} 
cells or tissue. Furthermore, nonimplantable tissue structures can be applied as external support devices (e.g., an extracorporal liver support when a compatible donor organ is not readily available [6, 7]), or engineered tissues can be used as in-vitro physiological models for studying disease pathogenesis and developing new molecular therapeutics (e.g., in-vitro assays for drug screening [7-9]).

For drug screening based on cell models, 2D cellular assays are mostly applied, using often well-described cell line models [10,11]. These assays can be performed quite efficiently in high-throughput screening (HTS) systems, but to date their value for predicting the clinical response of new agents, especially with respect to cancer therapy, is limited. This lack of predictability of 2D cellular assays is attributed to the fact that such systems do not mimic the response of the 3D microenvironment present in a tissue, or tumor, in vivo [10, 12-14]; therefore, 3D-cellular assays are required. Compared to 3D-tissue cultures intended for medical applications, here the size of the tissue construct is not a major problem, as smaller tissue constructs are also appropriate. The main challenge is the efficient, reproducible handling of a large quantity of tissue constructs in parallel.

The increasing market in highly specific biological pharmaceuticals such as antibodies, cytokines, growth factors or cells and tissue products highlighted the need for specific human relevant test systems on immunofunctions. In-vitro assays and transgenic animal models can be used in this situation. The development and use of immunotests in vitro, as well as transgenic animal models, must consider the remarkable specificity of the immune systems of different mammalian species. The investigation of effects on human patients at the research level of drug screening, in addition to tests on potency in samples of process development and production and an adapted preclinical risk assessment, requires human in-vitro immunotests to be conducted.

Established in-vitro tests based on acute lymphocyte reactions for induced cytokine release or cell proliferation of freshly prepared blood samples, such as mixed lymphocyte reaction, are inadequate for investigations into complex or long-term effects such as induced hypersensitivity and allergy.

The effects of immunogenicity or immunotoxicity must have been monitored in long-term culture under physiological and histological equivalency of secondary lymphatic organs using primary cells, tissue preparations, or immunocompetent cell lines. Recently, the use of transgenic animals mimicking isolated functions of the human immunosystem has been inadequate. In the future, immune cellbased in-vitro test systems may have to compete with transgenic animal models having a reconstituted human immune system.

The in-vitro generation of 3D tissue constructs requires not only a biological model (e.g., an adequate source of proliferative cells with appropriate biological functions; a protocol for proliferating cells while maintaining the tissue-specific phenotype) but also the further development of new culture strategies, including bioreactor concepts $[7,15,16]$. Bioreactors established for the cultivation of microbes or mammalian cells under monitored and controlled environmental and operational conditions (e.g., $\mathrm{pH}$, temperature, oxygen tension, nutrient supply) are mostly inapplicable to 3D tissue constructs. Furthermore, each type of tissue 
(e.g., skin, bone, blood vessels, cartilage) will likely require an individualized bioreactor design [15]. Therefore, tissue-specific bioreactors should be designed on the basis of a comprehensive understanding of biological and engineering aspects. Additionally, typical engineering aspects such as reliability, reproducibility, scalability and safety should be addressed [7, 16]. In the following sections, the key technical challenges are identified and an overview of existing culture systems and bioreactors used for tissue engineering is provided. These topics have been addressed to some extent by several authors [6, 7, 15-24], and also reviewed [25]; therefore, they will be discussed only briefly at this point. Particular focus will be given to the interaction between biological and engineering aspects and the special demands of using these reactor systems for drug screening. Using an artificial immunosystem as an example, it will be shown how an increased fundamental understanding of biological, biochemical, and engineering aspects can significantly improve the properties of 3D tissue constructs.

\section{2}

\section{Important Aspects for Bioreactor Design}

With regard to tissue engineering, bioreactors are used for cell proliferation on a small scale (e.g., for individual patients) and on a large scale (e.g., for allogeneic therapy concepts), to generate $3 \mathrm{D}$ tissue constructs from isolated and proliferated cells in vitro and for direct organ-support devices [23]. These bioreactors should enable the control of environmental conditions such as oxygen tension, $\mathrm{pH}$, temperature, and shear stress, as well as allowing aseptic operation (e.g., feeding and sampling). Furthermore, a bioreactor system should allow for automated processing steps. This is essential not only for controlled, reproducible, statistically relevant basic studies, but also for the future routine manufacture of tissues for clinical application or drug screening [7, 26]. In addition to these global requirements, specific key criteria for 3D tissue constructs based on cells and scaffolds must also be met, including the proliferation of cells, the seeding of cells onto macroporous scaffolds, nutrient (particularly oxygen) supply within the resulting tissue, and mechanical stimulation of the developing tissues [7].

The proliferation of cells represents the first step in establishing a tissue culture. Usually, cells harvested from a biopsy must be expanded by several orders of magnitude. Cell proliferation is quite often accompanied by the dedifferentiation of cells [27, 28], with small culture dishes (e.g., Petri dishes, 12-well plates, and T-flasks) being mainly used for cell expansion. As these devices allow an increase in cell number by a factor of only about 10 , several subcultivation steps are required. These are considered to be a major cause of dedifferentiation of cells. Recent studies have shown that microcarrier cultures performed in well-mixed bioreactor systems can significantly improve cell expansion [29-31].

A further critical aspect of a differentiated tissue is the extracellular matrix (ECM), as described by Alison Abbott (cited from [95]): "In mammalian tissues, cells connect not only to each other, but also to a support structure called the ECM. 
This contains proteins, such as collagen, elastin and laminin, that give tissues their mechanical properties and help to organize communication between cells embedded within the matrix. Receptors on the surface of the cells, in particular a family of proteins called the integrins, anchor their bearers to the ECM, and also determine how the cells interpret biochemical cues from their immediate surroundings. Given this complex mechanical and biochemical interplay, it is perhaps no surprise that researchers will miss biological subtleties if the cells they are studying grow only in flat layers. But providing an appropriate environment in which to culture cells in three-dimensions is no easy matter (...). Some researchers use simple gels consisting of collagen, whereas others make their own gels by extracting ECM material from relevant tissues. Another popular option is the commercially available Matrigel, which consists of structural proteins such as laminin and collagen, plus growth factors and enzymes, all taken from mouse tumours." [94, 95]. Further 3D (mostly macroporous) scaffolds used for tissue engineering have been discussed previously. The cell seeding of scaffolds is an important step in establishing a 3D culture in a macroporous scaffold, as not only seeding at high cell densities but also a homogeneous distribution of cells within the scaffold is essential [32-34]. Several techniques for cell seeding have been discussed by Martin et al. [7].

A sufficient supply of nutrients, together with the removal of toxic or inhibitory substances, is crucial for long-term culture to control a constant and defined environment. In 2D "flat culture", the formation of a suitable microenvironment is disturbed by convection of the culture supernatant and the periodically exchanged media. Cell migration and interaction is limited on the 2D-culture surface, and is more or less defined by the initial seeding of cells or resuspension and may be suitable for single-layer epithelioid tissues based on a high proliferative capacity. Perfusable and cell migrational voluminous matrices - the so-called 3D-matrices - support the formation of local microgradients, cell migration, cell-cell-activation, leading to coordinated proliferation aggregation, the initialization of tissue forming, and tissue polarization.

All kinds of flows needed for long-term supply, such as transfusion, perfusion, circulation and convection, disturb the formation of guiding microgradients. For an ideal microenvironment, it is vital to ensure the correct balance of minimal, yet sufficient, perfusion and a maximum of self-conditioning. Sufficient perfusion ensures an optimum of nutrient and metabolite concentrations. Inhomogeneity in oxygen tension, and local accumulations of cytokines and chemokines, triggers chemotaxis and cell activation and differentiation [101, 102].

Furthermore, the size of most engineered tissues is limited as they do not have their own blood system and the cells are supplied only by diffusion $[8,25,35]$. Oxygen supply is particularly critical, as only cell layers of 100-200 $\mu \mathrm{m}$ thickness can be supplied by diffusion [36]. However, as tissue constructs should have larger dimensions, mass-transfer limitations represent one of the greatest engineering challenges [25].

Various studies have shown that mechanical stimulation (e.g., mechanical compression, hydrodynamic pressure and fluid flow, which are important 
modulators of cell physiology) can have a positive impact on tissue formation [37], particularly in the context of musculoskeletal tissue engineering, cartilage formation, and cardiovascular tissues [19, 38-45]. As yet, however, little is known about the specific mechanical forces or the ranges of application, such as magnitude, frequency, continuous or intermittent, and duty cycle [7, 17]. Further studies of these factors must be coupled with quantitative and computational analyses of physical forces experienced by cells and changes in mass transport induced by the method used.

\section{3}

\section{Culture Systems and Bioreactors Used in Tissue Engineering}

An overview of the culture systems and bioreactors used for the engineering of 3D tissue constructs, including cell maintenance, proliferation, and tissue formation, is illustrated schematically in Figure 2.1a-c.

Culture systems developed for the monolayer culture of adherent cells (T-flasks, Petri dishes, multiwell plates) are normally used for cell maintenance and proliferation. These systems allow for sterile handling procedures and are easy to use, disposable, and inexpensive [46]. By contrast, they require individual handling, for example in stages of medium exchange and cell seeding, and their usefulness is limited when large quantities of cells are required [15], though this can be overcome to some extent by using sophisticated robotics [7]. In addition, environmental parameters such as $\mathrm{pH}, \mathrm{pO}_{2}$, and temperature cannot be controlled. A further drawback is the limited increase in cell number (approximately 10- to 20-fold during cultivation); consequently, the generation of a large number of cells requires several enzymatic subcultivation steps, accompanied by an increased passage number and cell dedifferentiation. In recent studies small well-mixed bioreactors (e.g., shake flasks, stirred vessels and "super spinner") have been suggested for cell proliferation in which the cells are grown on microcarriers [29-31]. These systems have been used for the cultivation of encapsulated cells $[27,28]$ or neural stem cells in single-cell suspension culture [47].

3D tissue cultures can be performed in fixed-bed and fluidized-bed bioreactors, with the cells being immobilized in macroporous carriers or in networks of fibers arranged in a column so that they are either packed (fixed-bed) or floating (fluidized-bed). The column is permanently perfused with a conditioned medium contained in a reservoir, mostly using a circulation loop. These types of reactor are very efficient for the long-term cultivation of mammalian cells to produce biopharmaceuticals, such as monoclonal antibodies, recombinant drugs including tissue plasminogen activator (tPA) and erythropoietin (EPO), or recombinant retroviruses for gene therapy [48-50]. For tissue engineering, the reactors have been investigated for several applications, including the cultivation of "liver" cells as an extracorporeal liver device [6, 18, 51], the proliferation of stem cells [52-54], the cultivation of cardiovascular cells [19] and cartilage cells [17], or as an in-vitro human placental model [55]. 
(a)
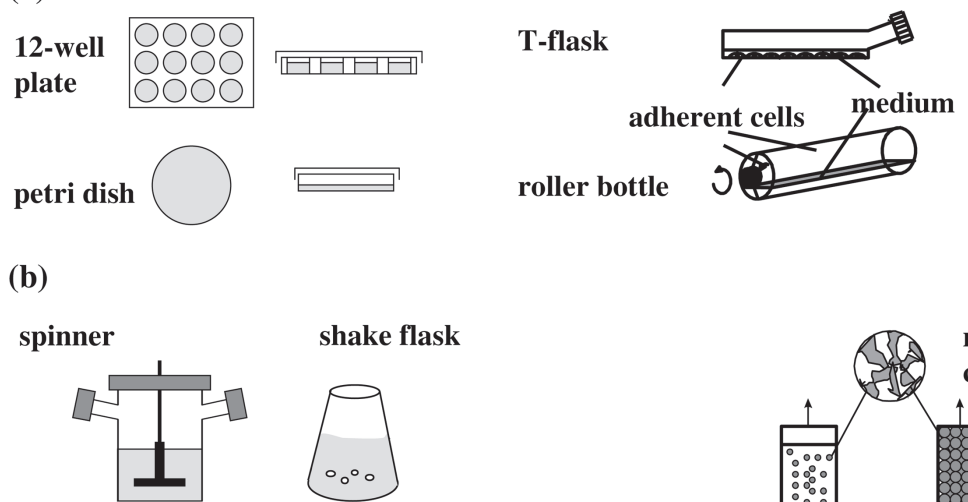

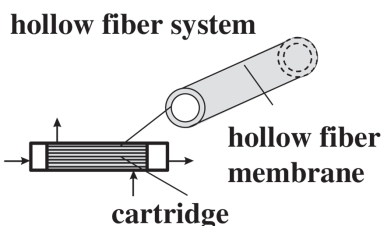

(c)

rotating wall vessel

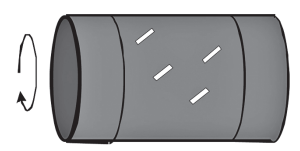

flat membrane system gas permeable $\mathrm{O,OOOQ}$ membrane culture hollow fiber membrane chamber for substrate supply

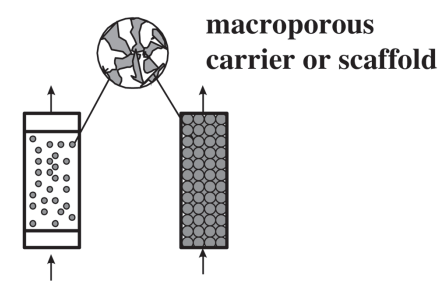

fluidized fixed bed bed

Fig. 2.1 An overview of cell culture systems used in tissue engineering (adapted and modified from [25]). (a) Systems used for routine cultivation within an incubator, where the cells grow mainly in monolayer (e.g., 12-well-plates, Petri dishes, T-flasks or roller bottles). (b) Culture systems developed mainly for cultivation of mammalian cells,

\section{flow chamber with} special inserts

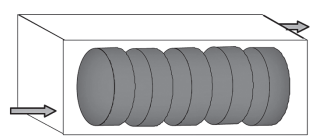

flow chamber for cylindrical tissues

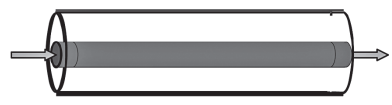

which were adapted for cultivation of tissue cells in three-dimensional structures (e.g., spinner and shake flasks, membrane-based systems such as hollow-fiber reactors or fluidized- and fixed-bed reactors). (c) Culture systems designed especially for tissue engineering mimicking the special demands of a three-dimensional tissue.

In membrane bioreactors, including hollow-fiber reactors [56], the miniPerm system [57] or the tecnomouse [58], cells are cultivated at tissue-like densities in a compartment which contains one or several types of membrane for nutrient and oxygen supply and removal of toxic metabolites. Hollow-fiber systems are widely used in the production of biopharmaceuticals, including monoclonal antibodies. Several examples of modified membrane bioreactors exist for the 3D culture of tissue cells, including hepatocytes [6, 59-64], skin cells [65] or other human cells $[58,66]$. 
Most of the culture systems and bioreactors discussed so far were first developed for the cultivation of mammalian cells, and subsequently adapted to the engineering of 3D tissue constructs. However, apart from some exceptions, they cannot easily be used in the generation of implantable tissue constructs, as each type of tissue intended for implantation (e.g., skin, heart valve, blood vessel, cartilage) requires a different geometric structure and a specific bioreactor design. One of the most prominent culture systems is the rotating-wall vessel [32], in which a construct remains in a state of free-fall through the medium with a low shear stress and a high mass transfer rate. This system has a wide range of practical applications [7, 15, 67]. A multipurpose culture system was introduced by Minuth et al. [68] for perfusion cultures under organotypic conditions. In this situation, several tissue carriers can be placed inside a perfusion container and, depending on the type of tissue-specific cell required, different supports can be selected. A perfused flow-chamber bioreactor with a new concept for aeration has been recently introduced $[44,69]$ in which tissue-specific inserts for various types of tissue (e.g., cartilage, skin, bone) can be applied.

In addition to these examples of multipurpose bioreactors, numerous tissuespecific culture systems have been suggested and reviewed [7, 8, 16-19, 22, 23, $35,59,70-72]$. Unfortunately, the majority of these have been custom-made, with only very few having been commercialized.

\section{4}

\section{The Operation of Bioreactors}

Bioreactors allow for different process strategies including batch, fed-batch, or continuous cultivation (Figs. 2.2 and 2.3).

Continuous perfusion, in particular, enables cultivation to be carried out under constant and controlled environmental conditions [44, 51, 68, 69, 73, 74]. Martin et al. [7] summarized some of the effects of direct perfusion on tissue-specific properties such as growth, differentiation and mineralized matrix deposition by bone cells, the proliferation of human oral keratinocytes, rates of albumin synthesis by hepatocytes, the expression of cardiac-specific markers by cardiomyocytes, and glucosaminoglycan (GAG) synthesis and matrix formation by chondrocytes (Fig. 2.4) [69].

On the other hand, a bioreactor system becomes more complex when additional features such as feeding pumps, vessels for fresh and spent medium, and control strategies are required, particularly in the case of mechanical stimulation. With regard to the formation of an implantable tissue, the bioreactor system must be integrated into the entire cultivation scheme, including biopsy, proliferation (cell expansion, usually in T-flasks), cell seeding of the bioreactor, tissue formation, and delivery to the site of application (e.g., the hospital). This is particularly important with regard to the manufacture of engineered tissue constructs for clinical applications, when good manufacturing practice (GMP) requirements must also be met $[15,16]$. 
$60 \mid 2$ An Overview on Bioreactor Design, Prototyping and Process Control

(a)

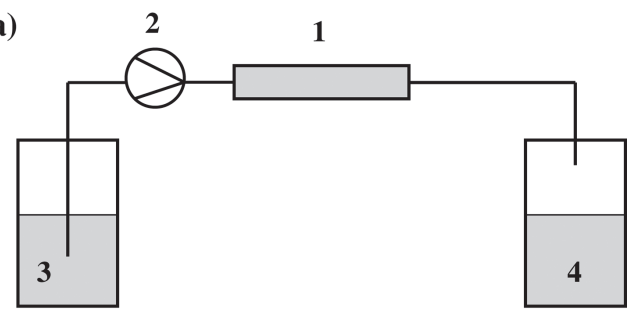

(b)

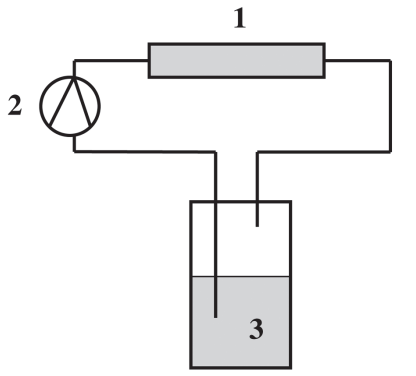

(c)

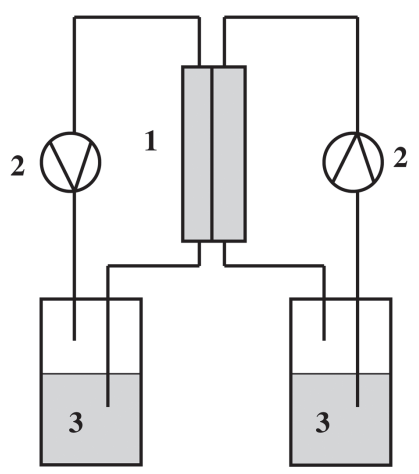

Fig. 2.2 The operation of tissue culture systems.

(a) Fresh medium is pumped continuously through the culture unit in a plug-flow. The required flow rate is determined by the substrate demands (especially oxygen) of the cells ( $1=$ culture unit; 2 = circulation pump; 3 = feed medium; 4 = spent medium).

(b) Medium is pumped continuously from a medium vessel through the cultivation unit and back. The medium in the medium vessel can be changed at intervals ( 1 = culture unit; 2 = circulation pump; 3 = medium vessel). (c) The culture unit consists of two culture chambers separated by a semipermeable membrane. Each culture chamber is supplied with fresh medium from an individual medium vessel. This technique is intended for the co-cultivation of different types of cells ( 1 = culture unit; $2=$ circulation pumps; 3 =medium vessels). 


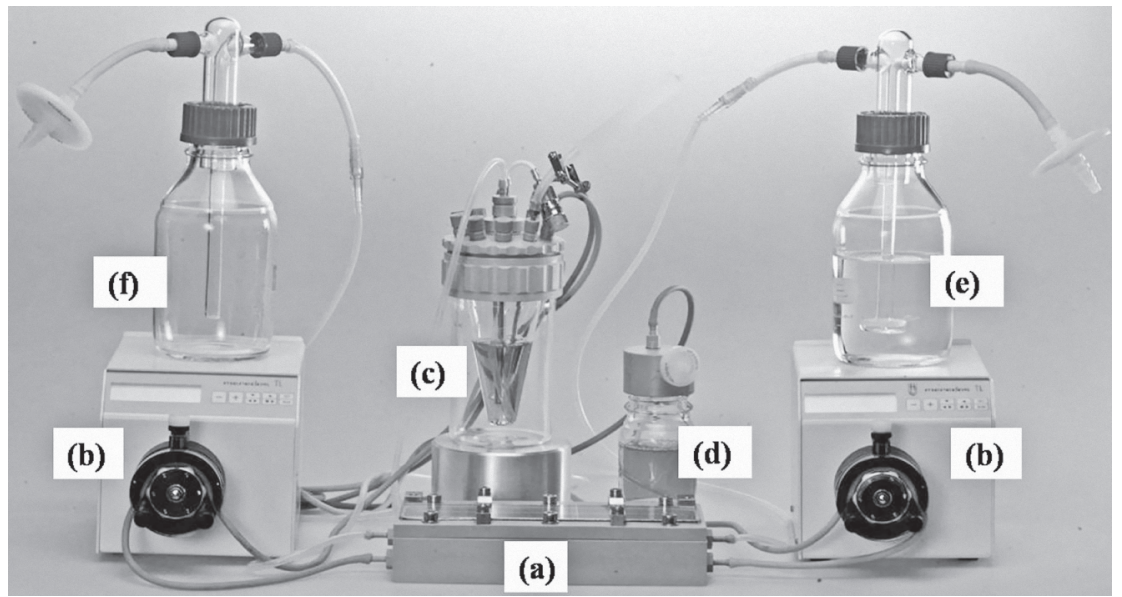

Fig. 2.3 The set-up of a flow-chamber bioreactor system to cultivate cartilage-carrier-constructs. The system consists of: (a) a flow chamber with inserts for tissue constructs; (b) peristaltic pumps for medium circulation; (c) a medium vessel; (d) a medium exchange bottle; (e) a humidifier; and (f) a flask to trap the exhaust gas. This set-up refers to a culture unit indicated in Fig. 2.1c (flow chamber with special inserts) operated according to the operation mode shown in Fig. 2.2b.

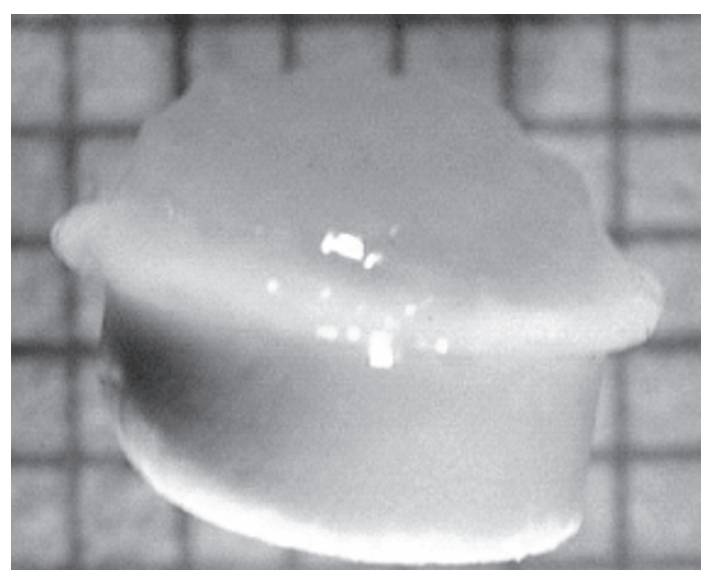

Fig. 2.4 Photograph (side view) of a cartilage-carrier-construct after cultivation in a flow chamber bioreactor on scale paper (scale $1 \mathrm{~mm}$ ) (for comparison, see [69]). 
The importance of handling a large quantity of tissue constructs in parallel has already been addressed in Section 2.1. Most systems discussed so far do not fulfill this requirement; rather, they are mostly applicable for a specific tissue construct of a desired size, to provide a controlled environment, and to enable a continuous supply of nutrients and oxygen as well as the removal of metabolites. Some systems were successfully applied for in-vitro drug studies [45, 55, 67, 74, 75], but these proved mostly to be unsuitable for handling a magnitude of culture units in parallel, as the need for additional devices such as pumps, tubes, medium reservoirs and aeration units ballooned.

As an alternative, tissue culture units especially intended for HTS have been developed, and included the multicellular spheroid model [11, 77, 78], microelectrode arrays ("Biology on a Chip" [79-82]), the cultivation of organ slices [83], or multilayered post-confluent cell culture [84]. The specific features of these techniques are discussed at length in the following sections. Most of these techniques are well suited to the cultivation of small tissue constructs, and it could be shown that tissue-specific functions were maintained satisfactorily. The lack of environmental control is seen as the main drawback of these systems; for example, the exchange of medium occurs mostly in batch mode, which leads to a constantly changing environment. A continuous exchange of medium under controlled conditions, such as in bioreactors for tissue constructs, is seldom achieved. Hence, the future challenge will be to combine the advantages of both approaches - to have a "conventional" bioreactor design for tissue constructs on the one hand, and HTS-culture techniques for 3D-constructs on the other hand.

2.6

Modeling of Bioreactor Systems for Tissue Engineering

The appropriate molecular and macroscopic architecture of 3D tissue constructs is essential when producing a phenotypically appropriate tissue [8]. The exact local conditions experienced by the cells must be understood, yet in many cases the culture systems and bioreactors used for 3D tissue culture have not been optimized in this respect. Several parameters, such as perfusion rate, flow conditions, shear stress, and compression magnitude, have been varied, quite often by using a trial-and-error approach. Furthermore, different conditions must be examined accurately with regard to their effect. For example, hydrostatic pressure applied during cartilage culture can lead to an improved mass transfer of small and large molecules into the cartilage matrix, but can also induce a mechanical stimulation of embedded cells.

As an example, mass transfer effects within a bioreactor designed for the cultivation of artificial blood vessels will be discussed in order to provide a deeper 
understanding of the physiological situation of the cells, especially with regards to oxygen supply within the reactor system. Oxygen can be supplied to the cells within the vessel matrix only by diffusion, as the vessel wall is not vascularized. As a direct measurement of oxygen concentration within the vessel matrix is not possible, the only way to obtain a better understanding of the oxygen concentration profile within the vessel matrix is to develop a mathematical model considering the mass transfer limitations on both sides of the vessel, as well as within the vessel matrix. The model assumptions are described in Figure 2.5a, while Figure 2.5b shows the radial oxygen profile within the vessel wall for different cell numbers. This indicates that, over the radius of the vessel, the oxygen concentration decreases rapidly, depending on the number of immobilized cells.

For cell densities of approximately $4 \times 10^{7} \mathrm{~mL}^{-1}$, severe oxygen limitation must be expected, whereas for cell densities of $10^{8} \mathrm{~mL}^{-1}$ (a tissue-like cell density) the penetration depth for oxygen is less than $100 \mu \mathrm{m}$. As the thickness of vessels used experimentally at present is approximately $1 \mathrm{~mm}$, an appropriate cell density with sufficient oxygen supply is about $10^{7} \mathrm{~mL}^{-1}$ of the vessel matrix. Further detailed simulations showed that the flow rate had no significant effect on the oxygen profile within the vessel wall, as the main mass transfer resistance is not in the boundary layer medium/vessel wall, but rather is within the vessel wall. Other parameters (e.g., vessel thickness, vessel inner radius and/or length) were also of minor importance. It can be concluded from these results that the number of cells within the vessel matrix and/or the thickness of the vessel matrix, which is not perfused, are strongly limited. These findings agree well with those of investigations into the cell penetration depth in macroporous carriers (using a NMR technique), and were in the range of 100-200 $\mu \mathrm{m}[36,85]$.

To prove further how much oxygen is supplied from the outer medium (which is not flowing), a corresponding model was formulated. The vessel wall was described by a plate geometry, with the further assumption of one-dimensional diffusion without reaction. From Figure 2.5c it can be concluded that the oxygen concentration in the outer vicinity of the vessel decreases very rapidly, so that the oxygen contribution from this side may be neglected.

This small example underlines the importance of theoretical considerations regarding mass transfer effects in 3D tissue cultures. Therefore, experimental studies should always be supported by simulation methods such as computational fluid dynamics (CFD), or the finite-element approach. Several examples underline the potential of an integrated study of mechanical and biomechanical factors that control the functional development of tissue-engineered constructs [86-92], and this approach will undoubtedly significantly improve bioreactor design in the near future. 
642 An Overview on Bioreactor Design, Prototyping and Process Control

(a) outer medium reservoir $c_{R}(t, x, r) \uparrow$

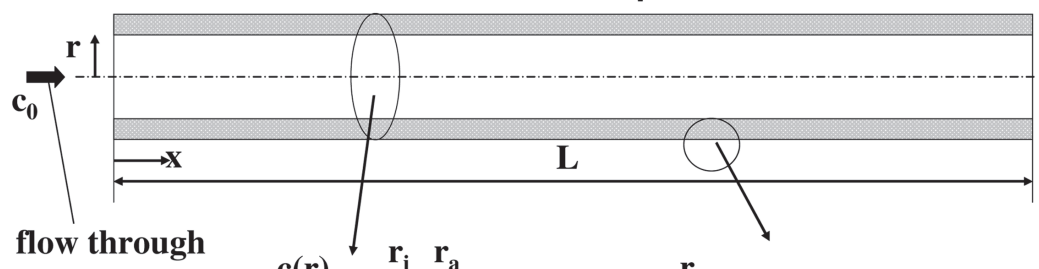

the vessel
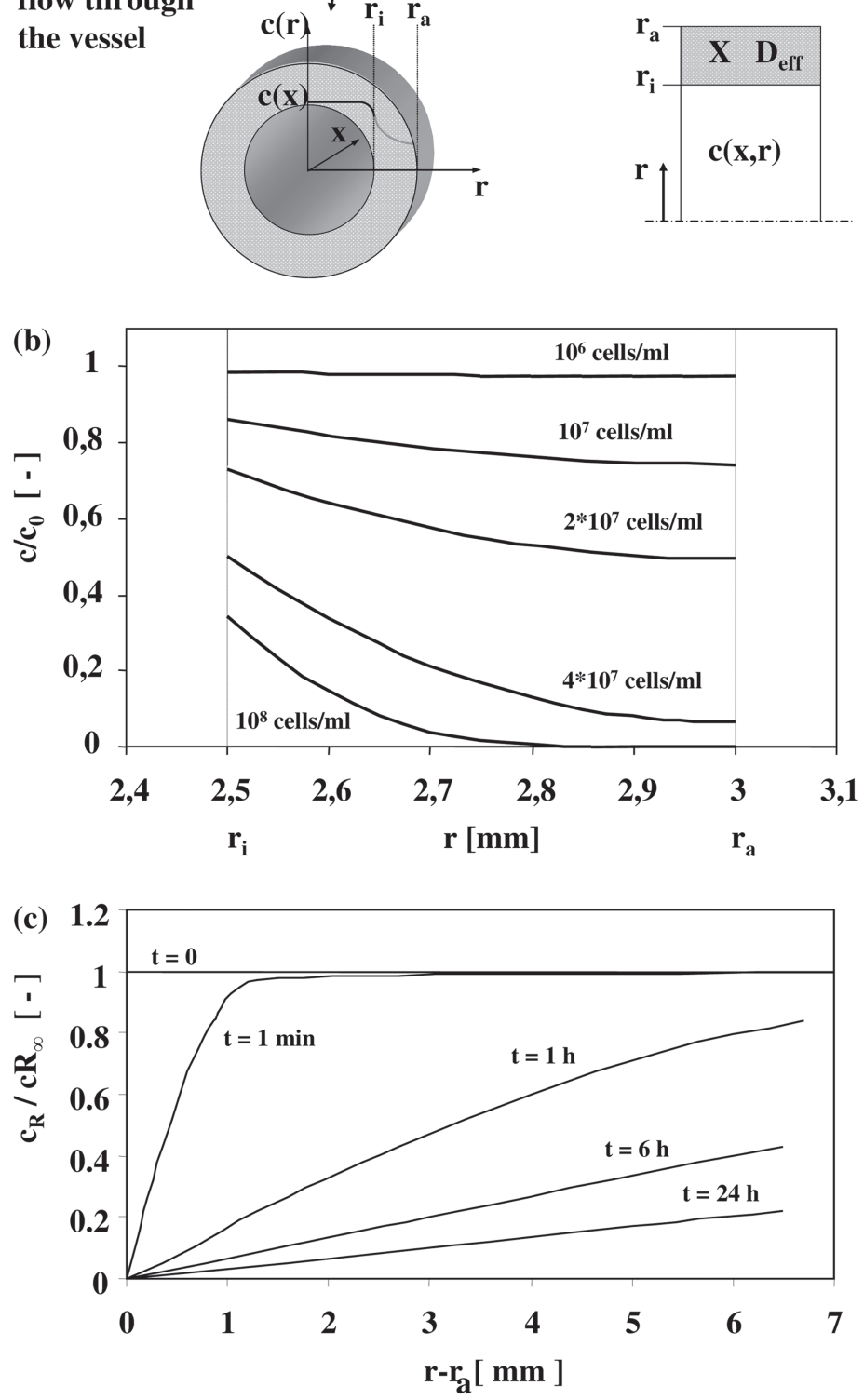

Fig. 2.5 (legend see p. 65) 
2.7

\section{The Artificial Immune System}

In vivo, immunogenicity and effects of immunotoxicity are localized in primary immune organs such as bone marrow or thymus, or secondary immune organs such as the lymph nodes and spleen, and spread into the peripheral tissues of the body, such as the skin and gut [106]. Tissue engineering approaches can be used to remodel cascades of cellular interactions in vitro. Recently, ex-vivo-generated and cultivated lymphatic cells have been used for immune cell therapies (e.g., adoptive immune responses, immune tolerance), but solid lymphoid tissue might also be a new substrate for regenerative medicine, in future. The implantation of artificial tissue-engineered lymphatic constructs in mice was recently described [112].

Due to the limitations of assays using suspended lymphocytes or native tissue biopsy preparations, it is essential that immunofunctions are monitored in longterm cultures, using in-vitro-designed complex multicellular systems of different cell types in tissue-like structures, termed "organoids". Organoids can be defined as artificial organ structures that are formed either by step-by-step reconstruction or by induced self-organization and self-assembly, and which demonstrate integrated organ functions in in-vivo equivalency. These organoids are generated in 3D culture systems, assisted by matrices for the initial seeding of cells and sustained support of cell interaction. Organoids overcome the limitations of "flat biology" in vitro $[93,98]$; embedding of the matrices supports 3D cell-cell interactions and the formation of larger cell aggregates [99].

Fig. 2.5 Theoretical considerations of the oxygen supply within perfused artificial blood vessels.

(a) The concept of the model. The vessel with an outer radius $r_{\mathrm{a}}$ and an inner radius $r_{\mathrm{i}}$ is perfused by a flow rate with an inlet oxygen concentration, $c_{0}$. The outer lumen is not perfused, and the oxygen concentration $c_{R}(t, x, r)$ in the outer medium depends on time and position. The oxygen concentration $c(x, r)$ in the inner medium flow and in the wall of the vessel depends on radius $r$ and the length parameter $x$. Oxygen uptake within the wall may change with time due to the growth or death of cells; however, this process can be regarded as slow. It is further assumed that the cells are distributed homogeneously within the cell wall. A diffusion coefficient $D_{\text {eff }}$ is introduced to describe diffusion within the wall. (b) The oxygen profile within the vessel. The complex model describing the oxygen profile within the inner lumen of the vessel and the vessel wall contains the oxygen uptake kinetic of the cells, the diffusion of oxygen in the vessel wall, and the mass transfer resistance from the flow in the center of the lumen to the inner radius. (c) The oxygen profile around the vessel. In order to prove how much oxygen is supplied from the outer medium which is not flowing, a corresponding model was formulated with the following assumptions. The vessel wall was described by a plate geometry; with the further assumption of one-dimensional diffusion without reaction, the following differential equations and boundary conditions, with $D$ as the diffusion coefficient for oxygen in the medium, are valid. Parameters: flow rate $=6 \mathrm{~mL} \mathrm{~min}^{-1}$; diffusion coefficient oxygen in membrane $D_{\text {eff }}=8.9 \mathrm{~mm}^{2} \mathrm{~h}^{-1}$; diffusion coefficient oxygen in medium $D=11.16 \mathrm{~mm}^{2} \mathrm{~h}^{-1}$. 
Remodeling the cellular interactions in dynamic tissues such as lymph nodes, spleen or endothelial-blood complexes requires controlled perfusion and mixing of the suspended mobile cells with matrix-bound immobile cells. Cell mixing enhances the probability of statistically distributed, rare and highly specific but much-needed initial cell-cell contacts and interactions, and for this perfusable matrices of sufficient porosity and migrational support are needed. The cell suspension can be applied continuously, periodically, or as a single event; moreover, the cell suspension can be reused in circulation for better stochastics.

The artificial lymph node (ALN) technology mimics the lymph node physiology by supporting the highly dynamic cellular self-organization, and the intensive interaction of mobile and stationary immune-competent cells and soluble antigens. The human lymph node acts like an interface between blood flow and the lymphatic fluid, transporting different types of cell populations. The lymphatic tissue ensures effective interaction of antigen-presenting cells (APC), for example, dendritic cells (DCs) and lymphocytes [106]. Antigen-loaded DCs of all body compartments enter the lymph nodes via lymphatic fluids, and adhere to the cellular network and inner surface of macroporous artificial ECM-equivalents. Naïve or resting $\mathrm{T}$ and $\mathrm{B}$ lymphocytes are transported by arterial blood flow and penetrate the endothelial barrier by cytokine- and chemokine-directed extravasation. The T lymphocytes then migrate through the lymphatic tissue to achieve close contact

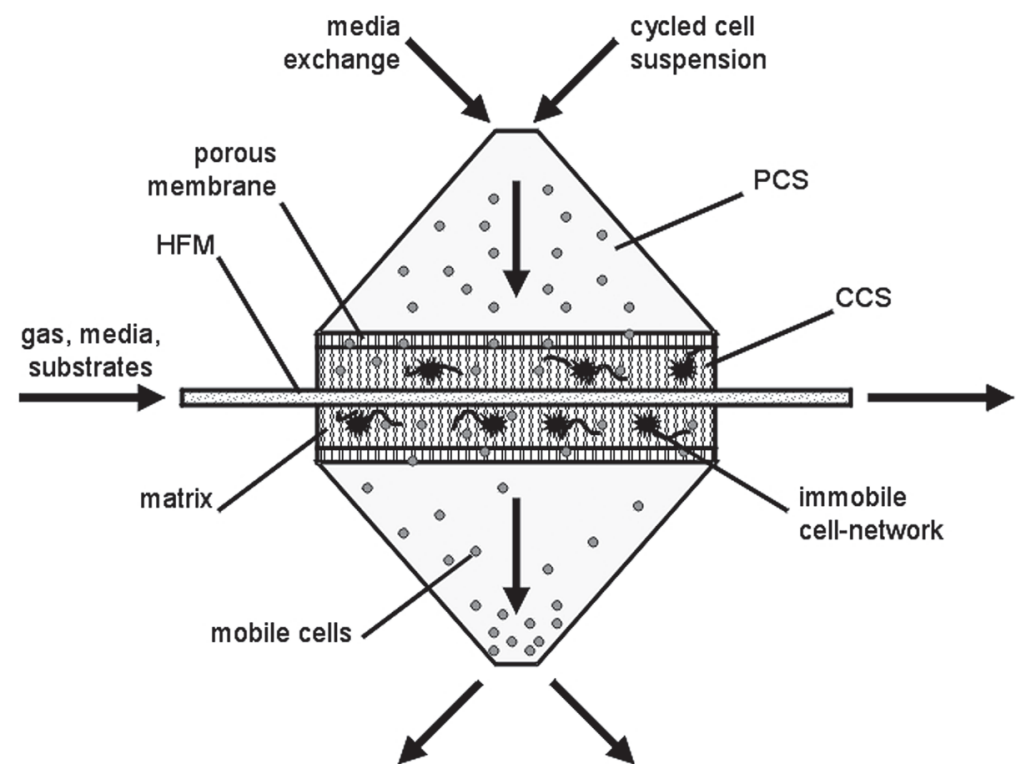

Fig. 2.6 Concept of mobile and immobile cell phases interacting in the artificial lymph node bioreactor. The suspended lymphocytes pass the central culture space (CCS) and come into close contact with the immobile dendritic cell network in the embedding matrix of the CCS. $\mathrm{HFM}=$ hollow-fiber membrane. 
with the immobilized APC for induction. The B lymphocytes form distinct B-cell areas, where they await antigen and co-stimulation by activated $\mathrm{T}$ cells.

As a technical equivalent, the ALN-bioreactor integrates mobile and immobile cell phases for effective interaction (Fig. 2.6). A central culture space (CCS) of $500 \mu \mathrm{L}$ (scalable up to $4 \mathrm{~mL}$ ) is supplied by a planar set of microporous hollow fibers for oxygenation and $\mathrm{pH}$ control. The CCS is matrix-filled and supported by planar macroporous membranes that allow continuous transfusion with media and cells from the peripheral culture space (PCS). Defined perfusion rates ensure adhesion and migration, and the media and cell suspension are continuously transfused in cyclic fashion to ensure long-term cultivation.

The CCS and PCS are designed in terms of geometry and transfusion velocity for a long and effective residence time of cells in the matrix, but a short residence time in the supporting fluids.

The application of suspended T lymphocytes and B lymphocytes is later restricted to a defined period of culture time. The transfusion of cells and media exchange and dilution is controlled independently (Fig. 2.7).

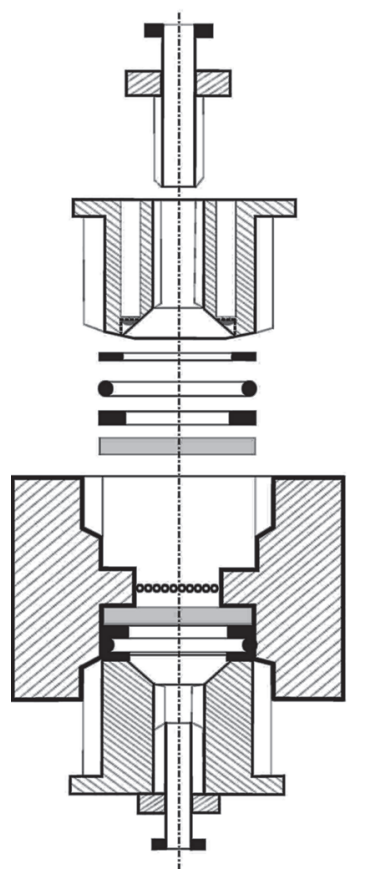

Fig. 2.7 Design of the artificial lymph node bioreactor in cross-sections and 3D shape. The central culture space (CCS) is supported by microporous hollow-fiber membranes for media and gas supply. For stabilization, the matrix-filled CCS is separated from the outer
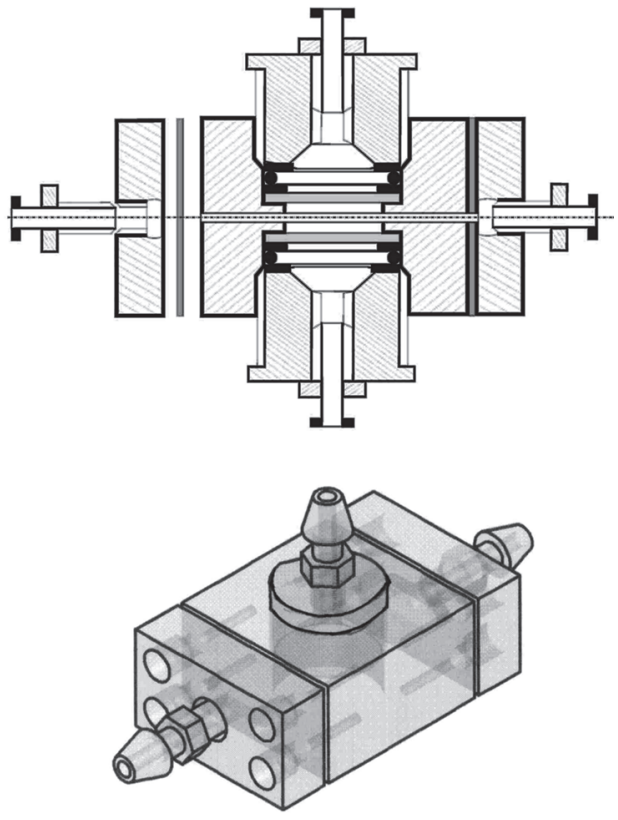

culture space by a macroporous membrane. The geometry of culture spaces and supporting fluidics is optimized for a maximum residential time in the CCS and efficient, but gentle, cell transportation in the peripheral culture space. 
Supporting matrices for the CCS need to be perfusable, cell-adhesive, and cell-migrational. In contrast to biohybrid implant technology (e.g., cartilage), biodegradability is irrelevant, but cell proliferation and the growth of organoids is necessary. Matrix sheets of nonwoven fibers (polyamides), hygrogels (peptides, agaroses, alginates, fibrin) and sponges (collagens) are particularly suitable for this purpose. Matrix performance is defined by the composition and structural properties on nanometer and micrometer scales.

2.7.2

\section{Microenvironment}

Cellular interaction and activation is controlled by the local microenvironment. A good balance of moderate perfusion and diffusion limitation ensures the formation of local microgradients in the CCS. As with many hormones, cytokines and growth factors have both autocrine and paracrine effects [105], but in contrast to hormones most of them function on a short track in the cellular neighborhood, or by direct cell-cell contact only. An overlay of different metabolite and factor microgradients forms distinct niches for cell differentiation, activation or energy. The differentiation and activation of hematopoietic stem cells and mature lymphocytes is biased by distinct levels of factors, such as glucose, lactate, dissolved oxygen, and $\mathrm{pH}[96,97,100-102]$.

APC immobilized in the ECM form a cellular network and secrete chemokines for the attraction of highly migrational T lymphocytes [109-111]. The communication of APC and T cell, and the formation of immunological synapses, is driven by a set of cytokines $[103,104]$. Activated T lymphocytes are key players in antigenspecific co-stimulation of B cells to ensure sustained B-cell activation and antibody rearrangement and secretion.

The T-cell activation can switch into a humoral, antibody-driven or a cellular immune response, and is strongly influenced by interleukin (IL)-4, IL-10, tumor necrosis factor (TNF)- $\alpha$ and interferon (IFN)- $\gamma$. In addition to the given local microenvironment, immune responses can also be guided by additional supplementation.

\subsection{3}

\section{Monitoring}

The online monitoring of tissue morphogenesis and organoids in perfusion bioreactor culture is limited to a small set of parameters. They need to be described as "black boxes" during the culture period, and the readout is defined by histological endpoints. Process control is based on online-sensing of oxygen and $\mathrm{pH}$, and samples of culture supernatant are periodically harvested (at $12 \mathrm{~h}$ and $24 \mathrm{~h}$ ) to this purpose. New approaches of miniaturized fluorescence-based online sensing for 
$\mathrm{pO}_{2}, \mathrm{pCO}_{2}$ and $\mathrm{pH}$ can be implemented $[113,114]$. In perfusion culture, the $\mathrm{pH}$ and defined levels of dissolved oxygen, metabolites and factors in the PCS can be adjusted by media and gas exchange.

The monitoring of cytokines provides insight into cellular immunological processes. Successful antigen presentation leads to increased TNF- $\alpha$ concentrations, while the induced T-cell reaction is described by IFN- $\gamma$ release. Shifts in T-lymphocyte populations into humoral or cellular inductors are better described by a set of cytokines (the cytokine panel). A cellular immune response (TH1-response) is detected by increased levels of IL-2, IL-12 and IFN- $\gamma$ or TNF- $\alpha$. In contrast, IL-4, IL-5, IL-6, IL-10 and IL-13 describe a humoral response (TH2response) $[107,108]$.

Tissue formation of the generated organoids can be characterized after harvest and histological preparation. Histochemical and immune-histological staining of the matrix sheets allows investigations to be made of the tissue formation and cellular composition. To prove the development of germinal centers (GC) [106] as key structures for antibody maturation in vivo, hematoxylin and eosin (H\&E) staining or May-Gruenwald-Giemsa-staining can be used. The immune-specific detection of cell surface markers can identify lymphocytes (CD3, CD4, CD19, $\mathrm{CD} 20)$, and also verify the segregation of lymphocytes into T- and B-cell areas in the matrix. Ki-67 or BrdU-incorporation is indicative of cell proliferation, while key to the scheme is the histological confirmation of secreted or membrane-bound IgM/IgG and their spatial distribution.

Living cells can be prepared following the disintegration of organoids, and also for further cultivation, cell fusion and fluorescence-activated cell sorting (FACS). DNA and RNA preparations can be obtained by using microdissection technology, while new approaches in live cell-imaging technology, multiphoton microscopy and microtomography each allow the monitoring and characterization of cell migration, homing proliferation [115, 116], and tissue formation in situ [117].

\section{8}

\section{Conclusions}

An overall comparison of different culture methods clearly shows the advantages of 3D tissue constructs for drug screening. Bioreactors can provide a better process control by taking into account the different demands of cells during cultivation. Furthermore, they can provide the technical means of performing controlled studies aimed at understanding specific biological, chemical, or physical effects, or for drug screening. Moreover, bioreactors enable a safe and reproducible production of tissue constructs, and can also be used to study effects such as shear flow and/or hydrostatic pressure on the generation of tissues.

With regard to future clinical applications, the bioreactor system should be an advantageous method in terms of low contamination risk, ease of handling, and scalability. With regard to drug screening, it is important that bioreactor systems are designed which allow for the cultivation of a magnitude of small tissue samples 
or constructs in parallel (HTS), under controlled conditions. These devices should consist of disposable, inexpensive cultivation units implemented with hardware to control temperature and gas and medium supplies. Moreover, such devices should be capable of operating automatically and continuously, with minimal manipulation steps.

To date, the goals and expectations of bioreactor development have been fulfilled only to a limited extent, notably because bioreactor design in tissue engineering is not only very complex but is also at an early stage of development. In the future, an intimate collaboration between engineers and biologists should lead to an increased fundamental understanding of the complex issues that will impact on tissue formation in bioreactors. These advances should help to ensure that, in time, tissue engineering fulfils the expectations for revolutionizing drug screening tools and medical care.

\section{Acknowledgments}

The authors thank Dr.-Ing. Stephanie Nagel-Heyer and Katja Schmidt for their scientific input and help in the mathematical simulations.

\section{References}

1 Langer, R. Tissue engineering. Mol. Ther. 2000, 1, 12-15.

2 Langer, R. and Vacanti, J. P. Tissue engineering. Science 1993, 260, 920-926.

3 Prochazkova, J. Contribution of 'in vitro' assays to preclinical and premarketing testing in immunotoxicology. Cent. Eur. J. Public Health 1993, 1(2), 101-105.

4 Petersen, J. P., Rücker, A., von Stechow, D., Adamietz, P., Pörtner, R., Rueger, J. M., and Meenen, N. M. Present and future therapies of articular cartilage defects. Eur. J. Trauma 2003, 1, 1-10.

5 Bradlaw, J. A. Evaluation of drug and chemical toxicity with cell culture systems. Fund. Appl. Toxicol. 1986, 6(4), 598-606.

6 Chamuleau, R. A. Artificial liver support in the third millennium. Artif. Cells Blood Substit. Immobil. Biotechnol. 2003, 31, 117-126.

7 Martin, I., Wendt, D., and Heberer, M. The role of bioreactors in tissue engineering. Trends Biotechnol. 2004, 22, 80-86.

8 Griffith, L. G. and Naughton, G. Tissue engineering - current challenges and expanding opportunities. Science 2002, 295, 1009-1014.

9 Bhadriraju, K. and Chen, C. S. Engineering cellular microenvironments to improve cell-based drug testing. Drug Discov. Today 2002, 7(11), 612-620.

10 Balcarcel, R. R. and Clark, L. M. Metabolic screening of mammalian cell cultures using well-plates. Biotechnol. Prog. 2003, 19(1), 98-108. 
11 Kunz-Schughart, L. A., Freyer, J. P., Hofstaedter, F., and Ebner, R. The use of 3D cultures for high-throughput screening: the multicellular spheroid model. J. Biomol. Screen. 2004, 9(4), 273-285.

12 DeClerck, Y. A. and Neustein, H. B. The contribution of tissue culture to the study of solid tumors of childhood. Perspect. Pediatr. Pathol. 1987, 9, 214-243.

13 Balimane, P. V. and Chong, S. Cell culture-based models for intestinal permeability: a critique. Drug Discov. Today 2005, 10(5), 335-343.

14 Kaspers, G. J., Zwaan, C. M., Pieters, R., and Veerman, A. J. Cellular drug resistance in childhood acute myeloid leukemia. A mini-review with emphasis on cell culture assays. Adv. Exp. Med. Biol. 1999, 457, 415-421.

15 Ratcliffe, A. and Niklason, L. E. Bioreactors and bioprocessing for tissue engineering. Ann. N. Y. Acad. Sci. 2002, 961, 210-215.

16 Naughton, G. K. From lab bench to market: critical issues in tissue engineering. Ann. N. Y. Acad. Sci. 2002, 961, 372-385.

17 Darling, E. M. and Athanasiou, K. A. Articular cartilage bioprocesses and bioreactors. Tissue Eng. 2003, 9, 9-26.

18 Allen, J. W. and Bhatia, S. N. Improving the next generation of bioartificial liver devices. Semin. Cell Dev. Biol. 2002, 13, 447-454.

19 Barron, V., Lyons, E., Stenson-Cox, C., McHugh, P. E., and Pandit, A. Bioreactors for cardiovascular cell and tissue growth: a review. Ann. Biomed. Eng. 2003, 31, 1017-1030.

20 Godbey, W. T. and Atala, A. In vitro systems for tissue engineering. Ann. N. Y. Acad. Sci. 2002, 961, 10-26.

21 Morsi, Y. S., Birchall, I. E., and Rosenfeldt, F. L. Artificial aortic valves: an overview. Int. J. Artif. Organs 2004, 27, 445-451.

22 Park, K. D., Kwon, I. K., and Kim, Y. H. Tissue engineering of urinary organs. Yonsei Med. J. 2000, 41, 780-788.

23 Shachar, M. and Cohen, S. Cardiac tissue engineering, ex-vivo: design principles in biomaterials and bioreactors. Heart Fail. Rev. 2003, 8, 271-276.

24 Vunjak-Novakovic, G. The fundamentals of tissue engineering: scaffolds and bioreactors. Novartis Found. Symp. 2003, 249, 34-46.

25 Pörtner, R., Nagel-Heyer, St., Goepfert, Ch., Adamietz, P., and Meenen, N. M. Bioreactor design for tissue engineering. J. Bioeng. Biosci. 2005, 100(3), 235-245.

26 Nagel-Heyer, S., Goepfert, Ch., Morlock, M. M., and Pörtner, R. Relationship between gross morphological and biochemical data of tissue engineered cartilage-carrier-constructs. Biotechnol. Lett. 2005, 27, 187-192.

27 Malda, J., van Blitterswijk, C. A., van Geffen, M., Martens, D. E., Tramper, J., and Riesle, J. Low oxygen tension stimulates redifferentiation of dedifferentiated adult human nasal chondrocytes. Osteoarthritis Cartilage 2004, 12, 306-313.

28 Domm, C., Schünke, M., Christesen, K., and Kurz, B. Redifferentiation of dedifferentiated bovine articular chondrocytes in alginate culture under low oxygen tension. Osteoarthritis Cartilage 2002, 10, 13-22. 
29 Nagel-Heyer, S., Leist, Ch., Lünse, S., Goepfert, C., and Pörtner, R. From biopsy to cartilage-carrier constructs by using microcarrier cultures as sub-process. In: Proceedings of 19th ESACT meeting. Harrogate, UK, 2005, p. 139.

30 Malda, J., van den Brink, P., Meeuwse, P., Grojec, M., Martens, D. E., Tramper, J., Riesle, J., and van Blitterswijk, C. A. Effect of oxygen tension on adult articular chondrocytes in microcarrier bioreactor culture.

Tissue Eng. 2004, 10, 987-994.

31 Bardouille, C., Lehmann, J., Heimann, P., and Jockusch, H. Growth and differentiation of permanent and secondary mouse myogenic cell lines on microcarriers. Appl. Microbiol. Biotechnol. 2001, 55, 556-562.

32 Freed, L. E., Langer, R., Martin, I., Pellis, N. R., and Vunjak-Novakovic, G. Tissue engineering of cartilage in space. Proc. Natl. Acad. Sci. USA 1997, 94, 13885-13890.

33 Holy, C. E., Shoichet, M. S., and Davies, J. E. Engineering three-dimensional bone tissue in vitro using biodegradable scaffolds: investigating initial cell-seeding density and culture period. J. Biomed. Mater. Res. 2000, 51, 376-382.

34 Carrier, R. L., Papadaki, M., Rupnick, M., Schoen, F. J., Bursac, N., Langer, R., Freed, L. E., and Vunjak-Novakovic, G. Cardiac tissue engineering: cell seeding, cultivation parameters, and tissue construct characterisation. Biotechnol. Bioeng. 1999, 64, 580-589.

35 Kannan, R. Y., Salacinski, H. J., Sales, K., Butler, P., and Seifalian, A. M. The roles of tissue engineering and vascularisation in the development of micro-vascular networks: a review. Biomaterials 2005, 26, 1857-1875.

36 Fassnacht, D. and Pörtner, R. Experimental and theoretical considerations on oxygen supply for animal cell growth in fixed bed reactors. J. Biotechnol. 1999, 72, 169-184.

37 Butler, D. L., Goldstein, S. A., and Guilak, F. Functional tissue engineering: the role of biomechanics. J. Biomech. Eng. 2000, 122, 570-575.

38 Carver, S. E. and Heath, C. A. Increasing extracellular matrix production in regenerating cartilage with intermittent physiological pressure. Biotechnol. Bioeng. 1999, 62, 166-174.

39 Carver, S. E. and Heath, C. A. Influence of intermittent pressure, fluid flow, and mixing in the regenerative properties of articular chondrocytes. Biotechnol. Bioeng. 1999, 65, 274-281.

40 Hall, A. C., Urban, J. P. G., and Gehl, K. A. The effects of hydrostatic pressure on matrix synthesis in articular cartilage. J. Orthop. Res. 1991, 9 , $1-10$.

41 Jagodzinski, M., Cebotari, S., Tudorache, I., Zeichen, J., Hankemeier, S., Krettek, C., van Griensven, M., and Mertsching, H. Tissue engineering of long bones with a vascular matrix in a bioreactor. Orthopade 2004, 33, 1394-1400. 
42 Seidel, J. O., Pei, M., Gray, M. L., Langer, R., Freed, L. E., and Vunjak-Novakovic, G. Long-term culture of tissue engineered cartilage in a perfused chamber with mechanical stimulation. Biorheology 2004, 41, 445-458.

43 Yu, X., Botchwey, E. A., Levine, E. M., Pollack, S. R., and Laurencin, C. T. Bioreactor-based bone tissue engineering: the influence of dynamic flow on osteoblast phenotypic expression and matrix mineralization. Proc. Natl. Acad. Sci. USA 2004, 101, 11203-11208.

44 Nagel-Heyer, St. Engineering aspects for generation of three-dimensional cartilage-carrier-constructs. Books on Demand GmbH, Norderstedt, Germany, 2004.

45 Garvin, J., Qi, J., Maloney, M., and Banes, A. J. Novel system for engineering bioartificial tendons and application of mechanical load. Tissue Eng. 2003, 9(5), 967-979.

46 Morgan, J. R. and Yarmush, M. L. Tissue engineering methods and protocols. Humana Press, Totowa, NJ, 1999.

47 Sen, A., Kallos, M. S., and Behie, L. A. New tissue dissociation protocol for scaled-up production of neural stem cells in suspension bioreactors. Tissue Eng. 2004, 10, 904-913.

48 Fassnacht, D., Rössing, S., Singh, R., Al-Rubeai, M., and Pörtner, R. Influence of BCL-2 Expression on antibody productivity in high cell density hybridoma culture systems. Cytotechnology 1999, 30, 95-105.

49 Fussenegger, M., Fassnacht., D., Schwartz, R., Zanghi, J. A., Graf, M., Bailey, J. E., and Pörtner, R. Regulated overexpression of the survival factor bcl-2 in CHO cells increases viable cell density in batch culture and decreases DNA release in extended fixed-bed cultivation. Cytotechnology 2000, 32, 45-61.

50 Nehring, D., Gonzales, R., Czermak, P., and Pörtner, R. Mathematical model of a membrane filtration process using ceramic membranes to increase retroviral pseudotype vector titer. J. Membr. Sci. 2004, 237, 25-38.

51 Fassnacht, D., Rössing S., Stange, J., and Pörtner. R. Long-term cultivation of immortalised mouse hepatocytes in a high cell density fixed bed reactor. Biotechnol. Tech. 1998, 12, 25-30.

52 Noll, T., Jelinek, N., Schmid, S., Biselli, M., and Wandrey, C. Cultivation of hematopoietic stem and progenitor cells: biochemical engineering aspects. Adv. Biochem. Eng. Biotechnol. 2002, 74, 111-128.

53 Cabrita, G. J., Ferreira, B. S., da Silva, C. L., Goncalves, R., AlmeidaPorada, G., and Cabral, J. M. Hematopoietic stem cells: from the bone to the bioreactor. Trends Biotechnol. 2003, 21, 233-240.

54 Schubert, H., Garrn, I., Berthold, A., Knauf, W. U., Reufi, B., Fietz, T., and Gross, U. M. Culture of haematopoietic cells in a 3D bioreactor made of $\mathrm{Al}_{2} \mathrm{O}_{3}$ or apatite foam. J. Mater. Sci. Mater. Med. 2004, 15, 331-334.

55 Ma, T., Yang, S. T., and Kniss, D. A. Development of an in vitro human placenta model by the cultivation of human trophoblasts in a fiber-based bioreactor system. Tissue Eng. 1999, 5(2), 91-102. 
56 Davis, J. M. and Hanak, J. A. Hollow-fiber cell culture. Methods Mol. Biol. 1997, 75, 77-89.

57 Weichert, H., Falkenberg, F. W., Krane, M., Behn, I., Hommel, U., and Nagels, H. O. Cultivation of animal cells in a new modular minifermenter. In: Beuvery, E. C., Griffiths, J. B., and Zeijlemaker, W. P. (Eds.), Animal Cell Technology: Developments towards the 21st century. Kluwer Academic Publishers, The Netherlands, 1995, pp. 907-913.

58 Nagel, A., Effenberger, E., Koch, S., Lübbe, L., and Marx, U. Human cancer and primary cell culture in the new hybrid bioreactor system tecnomouse. In: Spier, R. E., Griffiths, J. B., and Berthold W. (Eds.), Animal Cell Technology: Products of today, prospects for tomorrow. Butterworth-Heinemann, Oxford, 1994, pp. 296-298.

59 De Bartolo, L. and Bader, A. Review of a flat membrane bioreactor as a bioartificial liver. Ann. Transplant. 2001, 6, 40-46.

60 Jasmund, I. and Bader, A. Bioreactor developments for tissue engineering applications by the example of the bioartificial liver. Adv. Biochem. Eng. Biotechnol. 2002, 74, 99-109.

61 Kulig, K. M. and Vacanti, J. P. Hepatic tissue engineering. Transpl. Immunol. 2004, 12, 303-310.

62 Gerlach, J. C. Development of a hybrid liver support system: a review. Int. J. Artif. Organs 1996, 19, 645-654.

63 Sielaff, T. D., Hu, M. Y., Amiot, B., Rollins, M. D., Rao, S., McGuire, B., Bloomer, J. R., Hu, W. S., and Cerra, F. B. Gel-entrapment bioartificial liver therapy in galactosamine hepatitis. J. Surg. Res. 1995, 59, 179-184.

64 Ostrovidov, S., Jiang, J., Sakai, Y., and Fujii, T. Membrane-based PDMS microbioreactor for perfused 3D primary rat hepatocyte cultures. Biomed. Microdevices 2004, 6(4), 279-287.

65 Prenosil, J. E. and Villeneuve, P. E. Automated production of cultured epidermal autografts and sub-confluent epidermal autografts in a computer controlled bioreactor. Biotechnol. Bioeng. 1998, 59, 679-683.

66 Marx, U., Matthes, H., Nagel, A., and Baehr, R. V. Application of a hollow fiber membrane cell culture system in medicine. Am. Biotechnol. Lab. 1993, 11, 26.

67 Zhau, H. E., Goodwin, T. J., Chang, S. M., Baker, T. L., and Chung, L. W. Establishment of a three-dimensional human prostate organoid coculture under microgravity-simulated conditions: evaluation of androgen-induced growth and PSA expression. In Vitro Cell Dev. Biol. Anim. 1997, 33(5), 375-380.

68 Minuth, W. W., Stöckl, G., Kloth, S., and Dermietzel, R. Construction of an apparatus for perfusion cell cultures which enables in vitro experiments under organotypic conditions. Eur. J. Cell. Biol. 1992, 57, 132-137.

69 Nagel-Heyer, S., Goepfert, Ch., Adamietz, P., Meenen, N. M., Petersen, J.-P., and Pörtner, R. Flow-chamber bioreactor culture for generation of three-dimensional cartilage-carrier-constructs. Bioproc. Biosyst. Eng. 2005, 27, 273-280. 
70 Ratcliffe, A. Tissue engineering of vascular grafts. Matrix Biol. 2000, 19, 353-357.

71 Risbud, M. V. and Sittinger, M. Tissue engineering: advances in in vitro cartilage generation. Trends Biotechnol. 2002, 20, 351-356.

72 Minuth, W. W., Strehl, R., and Schumacher, K. Tissue engineering from cell biology to artificial organs. Wiley-VCH Verlag, Weinheim, 2005.

73 Sittinger, M., Schultz, O., Keyser, G., Minuth, W. W., and Burmester, G. R. Artificial tissues in perfusion culture. Int. J. Artif. Organs 1997, 20, 57-62.

74 Nehring, D., Adamietz, P., Meenen, N. M., and Pörtner, R. Perfusion cultures and modelling of oxygen uptake with three-dimensional chondrocyte pellets. Biotechnol. Tech. 1999, 13, 701-706.

75 Koebe, H. G., Deglmann, C. J., Metzger, R., Hoerrlein, S., and Schildberg, F. W. In vitro toxicology in hepatocyte bioreactors-extracellular acidification rate (EAR) in a target cell line indicates hepato-activated transformation of substrates. Toxicology 2000, 154(1-3), 31-44.

76 Zeilinger, K., Sauer, I. M., Pless, G., Strobel, C., Rudzitis, J., Wang, A., Nussler, A. K., Grebe, A., Mao, L., Auth, S. H., Unger, J., Neuhaus, P., and Gerlach, J. C. Three-dimensional co-culture of primary human liver cells in bioreactors for in vitro drug studies: effects of the initial cell quality on the long term maintenance of hepatocyte-specific functions. Altern. Lab. Anim. 2002, 30(5), 525-538.

77 Thielecke, H., Mack, A., and Robitzki, A. A multicellular spheroid-based sensor for anti-cancer therapeutics. Biosens. Bioelectron. 2001, 16(4-5), 261-269.

78 Kelm, J. M., Ehler, E., Nielsen, L. K., Schlatter, S., Perriard, J. C., and Fussenegger, M. Design of artificial myocardial microtissues. Tissue Eng. 2004, 10(1-2), 201-214.

79 Park, T. H. and Shuler, M. L. Integration of cell culture and microfabrication technology. Biotechnol. Prog. 2003, 19(2), 243-253.

80 Stett, A., Egert, U., Guenther, E., Hofmann, F., Meyer, T., Nisch, W., and Haemmerle, H. Biological application of microelectrode arrays in drug discovery and basic research. Anal. Bioanal. Chem. 2003, 377(3), 486-495.

$81 \mathrm{Li}$, N., Tourovskaia, A., and Folch, A. Biology on a chip: microfabrication for studying the behaviour of cultured cells. Crit. Rev. Biomed. Eng. 2003, 31(5-6), 423-488.

82 Hoffman, R. M. The three-dimensional question: can clinically relevant tumor drug resistance be measured in vitro? Cancer Metastasis Rev. 1994, 13(2), 169-173.

83 Vickers, A. E. and Fisher, R. L. Organ slices for the evaluation of human drug toxicity. Chem. Biol. Interact. 2004, 150(1), 87-96.

84 Padron, J. M., van der Wilt, C. L., Smid, K., Smitskamp-Wilms, E., Backus, H. H., Pizao, P. E., Giaccone, G., and Peters, G. J. The multilayered postconfluent cell culture as a model for drug screening. Crit. Rev. Oncol. Hematol. 2000, 36(2-3), 141-157. 
85 Thelwall, P. E., Anthony, M. L., Fassnacht, D., Pörtner, R., and Brindle, K. M. Analysis of cell growth in a fixed bed bioreactor using magnetic resonance spectroscopy and imaging. In: Merten, O.-W., Perrin, P., and Griffiths, B. (Eds.), New Developments and New Applications in Animal Cell Technology. Kluwer Academic Publishers, The Netherlands, 1998, pp. 627-633.

86 Lima, E. G., Mauck, R. L., Shelley, H. H., Park, S., Ng, K. W., Ateshian, G. A., and Hung, C. T. Functional tissue engineering of chondral and osteochondral constructs. Biorheology 2004, 41, 577-590.

87 Raimondi, M. T., Boschetti, F., Falcone, L., Fiore, G. B., Remuzzi, A., Marinoni, E., Marazzi, M., and Pietrabiss, R. Mechanobiology of engineered cartilage cultured under a quantified fluid-dynamic environment. Biomech. Model. Mechanobiol. 2002, 1, 69-82.

88 Connelly, J. T., Vanderploeg, E. J., and Levenston, M. E. The influence of cyclic tension amplitude on chondrocyte matrix synthesis: experimental and finite element analyses. Biorheology 2004, 41, 377-387.

89 Sengers, B. G., Oomens, C. W. J., and Baaijens, F. P. T. An integrated finite-element approach to mechanics, transport and biosynthesis in tissue engineering. J. Biomech. Eng. 2004, 126, 83-91.

90 Williams, K. A., Saini, S., and Wick, T. M. Computational fluid dynamics modelling of steady-state momentum and mass transport in a bioreactor for cartilage tissue engineering. Biotechnol. Prog. 2002, 18, 951-963.

91 Mauck, R. L., Hung, C. T., and Ateshian, G. A. Modelling of neutral solute transport in a dynamically loaded porous permeable gel: Implications for articular cartilage biosynthesis and tissue engineering. J. Biomech. Eng. 2003, 125, 602-614.

92 Begley, C. M. and Kleis, S. J. The fluid dynamic and shear environment in the NASA/JSC rotating-wall perfused-vessel bioreactor. Biotechnol. Bioeng. 2000, 70, 32-40.

93 Anonymous. Good bye, flat biology? Nature 2003, 424, 861.

94 Griffith, L. and Swartz, M. A. Capturing complex 3D tissue physiology in vitro. Nat. Rev. Mol. Cell Biol. 2006, 7(3), 211-224.

95 Abbott, A. Biology's new dimension. Nature 2003, 424, 870-872.

96 Wilson, A. and Trumpp, A. Bone-marrow haematopoietic stem-cell niches. Nat. Rev. Immunol. 2006, 6(2), 93-106.

97 Mohtashami, M., and Zuniga-Pflücker, J. C. Cutting edge: three-dimensional architecture of the thymus is required to maintain delta-like expression necessary for inducing T-cell development. J. Immunol. 2006, 176, 730-734.

98 Bell, E. Why 3D is better than 2D. Nat. Rev. Immunol. 2006, 6(2), 87.

99 Lutolf, M. P. and Hubbell, J. A. Synthetic biomaterials as instructive extracellular microenvironments for morphogenesis in tissue engineering. Nat. Biotechnol. 2005, 23(1), 47-55.

100 Carswell, K. S. and Papoutsakis E. T. Extracellular pH affects the proliferation of cultured human $\mathrm{T}$ cells and their expression of the interleukin-2 receptor. J. Immunother. 2000, 23(6), 669-674. 
101 Carswell, K. S., Weiss, J. W., and Papoutsakis E. T. Low oxygen tension enhances the stimulation and proliferation of human T-lymphocytes in the presence of IL-2. Cytotherapy 2000, 2(1), 25-37.

102 Koller, M. R., Bender, J. G., Miller, W. M., and Papoutsakis, E. T. Reduced oxygen tension increases hematopoiesis in long-term culture of human stem and progenitor cells from cord blood and bone marrow. Exp. Hematol. 1992, 20(2), 264-270.

103 Dustin, M. L., Allen, P. M., and Shaw, A. S. Environmental control of immunological synapse formation and duration. Trends Immunol. 2001, 22(4), 192-194.

104 Li, Q. J., Dinner, A. R., Qi, S., Irvine, D. J., Huppa, J. B., Davis, M. M., and Chakraborty, A. K. CD4 enhances T-cell sensitivity to antigen by coordinating Lck accumulation at the immunological synapse. Nat. Immunol. 2004, 5, 791-799.

105 Thomson, A. The Cytokine Handbook. 3rd edn., Academic Press, London, 1998.

106 Janeway, C. A., Travers, P., Walport, M., and Shlomchik, M. Immunobiology: The Immune system in Health and Disease. 6th edn. Garland Science Publishing, New York, 2005.

107 Reddy, M., Eirikis, E., Davis, C., Davis, H. M., and Prabhakar, U. Comparative analysis of lymphocyte activation marker expression and cytokine secretion profile in stimulated human peripheral blood mononuclear cell cultures: an in vitro model to monitor cellular immune function. J. Immunol. Methods 2004, 293, 127-142.

108 Rodriguez-Caballero, A., Garcia-Montero, A. C., Bueno, C., Almeida, J., Varro, R., Chen, R., Pandiella, A., and Orfao, A. A new simple whole blood flow cytometry-based method for simultaneous identification of activated cells and quantitative evaluation of cytokines released during activation. Lab. Invest. 2004, 84, 1387-1398.

109 Moser, B. and Loetscher, P. Lymphocyte traffic control by chemokines. Nat. Immunol. 2001, 2(2), 123-128.

110 Bachmann, M. F., Kopf M., and Marsland B. J. Chemokines: more than just road signs. Nat. Rev. Immunol. 2006, 6(2), 159-164.

111 von Andrian, U. H. Introduction: chemokines - regulation of immune cell trafficking and lymphoid organ architecture. Semin. Immunol. 2003, 15, 239-241.

112 Suematsu, S. and Watanabe, T. Generation of a synthetic lymphoid tissuelike organoid in mice. Nat. Biotechnol. 2004, 22(12), 1539-1545.

113 Gao, F. G., Jeevarajan, A. S., and Anderson, M. M. Long-term continuous monitoring of dissolved oxygen in cell culture medium for perfused bioreactors using optical oxygen sensors. Biotechnol. Bioeng. 2004, 86(4), 425-433.

114 Kellner, K., Liebsch, G., Klimant, I., Wolfbeis, O. S., Blunk, T., Schulz, M. B., and Göpferich, A. Determination of oxygen gradients in engineered tissue using a fluorescent sensor. Biotechnol. Bioeng. 2002, 80(1), 73-83. 
782 An Overview on Bioreactor Design, Prototyping and Process Control

115 von Andrian U. H. and Mempel T. R. Homing and cellular traffic in lymph nodes. Nat. Rev. Immunol. 2003, 3, 867-878.

116 Helmchen, F. and Denk, W. Deep tissue two-photon microscopy. Nat. Methods 2005, 2(12), 932-940.

117 Müller, B., Riedel, M., and Thurner, P. J. Three-dimensional characterization of cell clusters using synchroton-radiation-based micro-computed tomography. Microsc. Microanal. 2006, 12, 97-105. 